\title{
Perbandingan Algoritma Fitness of Spring dan Algoritma Tabu Search pada Kasus Penjadwalan Perkuliahan
}

\author{
Aishiyah Saputri Laswi \\ Universitas Andi Djemma Palopo, Program Studi Teknik Informatika, Jln. Tandipau, Palopo, 91923, Indonesia \\ aishiyah.rustam@gmail.com
}

\section{INFORMASI ARTIKEL}

Dikirim: 13 Februari 2020

Diulas: 11 Maret 2020

Direvisi: 9 April 2020

Diterbitkan: 27 April 2020

Kata Kunci:

Algoritma Fitness

Algoritma Tabu Search

Analisis Perbandingan Kinerja

Jadwal Pengganti

\section{ABSTRAK}

Penyusunan jadwal perkuliahan merupakan hal yang sangat penting pada universitas untuk kelangsungan proses belajar mengajar program studi. Seperti halnya pada universitas Andi Djemma Palopo Program Studi Teknik Informatika. Seringnya terjadi kuliah pengganti untuk mengganti jadwal mata kuliah merupakan suatu hal yang kompleks mengingat jadwal yang sudah ada sebelumnya sudah tersusun dengan baik. Namun dengan adanya kuliah biasanya kesulitan untuk menentukan jadwal, hari, jam, ruangan dan kelas agar tidak terjadinya kuliah pengganti yang bermasaan dengan mata kuliah lainnya. Sehingga pada Studi Kasus kali ini peneliti membandingan dua metode yaitu, Metode fitness dan Algoritma tabu search untuk melihat kinerja pada saat penentuan jadwal pengganti. Nilai yang diperoleh dari hasil implementasi kedua metode diatas, dengan menggunakan metode fitness adalah 40 sedangkan untuk tabu search batasan nilai maksimum yang diperoleh dinilai akhir adalah 15 berdasarkan urutan dari jadwal mata kuliah sebelumnya dan mata kuliah yang akan diganti kehadirannya. Dengan demikian nilai yang diperoleh dengan menggunakan metode tabu search adalah dalam kategori normal dibanding dengan metode fitness yang berubah-ubah.dengan demikian peneliti dapat menyimpulkan bahwa nilai yang diperoleh tabu search lebih kecil sehingga baik digunakan untuk menentukan penjadwalan.

\section{Keywords:}

Fitness Algorithm

Taboo Search Algorithm

Performance Comparison Analysis

Substitute Schedule

\section{ABSTRACT}

The compilation of lecture schedules is very important at universities for the continuity of the teaching and learning process of study programs. Such as at Andi Djemma Palopo University, Informatics Engineering Study Program. Frequently occurring alternate lectures to change course schedules is a complex thing considering the pre-existing schedule is well organized. But with the lectures, it is usually difficult to determine schedules, days, hours, rooms, and classes so that, no alternate lectures are coinciding with other subjects. so that in this Case Study, the researcher compared two methods namely the Fitness Method and the Taboo Search Algorithm to see the performance when determining the replacement schedule. The values obtained from the results of the implementation of the two methods above, are with using the fitness method is 40 while for the taboo search the maximum value obtained is 15 , based on the order of the schedule of previous courses and courses that will be replaced. Thus, the value obtained by using the taboo search method is in the normal category compared to the changing fitness method. Thus, the researcher can conclude that the value obtained by the taboo search is smaller so that, it is good to be used to determine scheduling.

This is an open access article under the CC-BY-SA license.

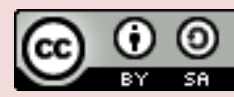

\section{Pendahuluan}

Jadwal perkuliahaan merupakan informasi yang wajib dibuat oleh program studi masing-masing setiap semesternya oleh perguruan tinggi [1]. Yang mana jadwal kuliah merupakan suatu perangkat utama dalam sistem akademik untuk menunjang berjalannya proses belajar mengajar dalam suatu perguruan tinggi. Jadwal kuliah disusun mulai dari awal sesmester sampai akhir semester untuk menjadi sebuah informasi bagi para 
mahasiswa dan dosen-dosen. Seperti pada contoh kasus Prodi Teknik Informatika Universitas Andi Djemma Palopo.

Dalam membuat penjadwalan ada beberapa hal yang harus menjadi perhatian misalnya dosen, kelas, ruang belajar dan waktu perkuliahan [2]. Semua hal yang disebutkan diatas merupakan komponen wajib yang harus diperhatikan agar tidak ada proses kuliah dilaksanakan secara bersamaan. Jadwal perkuliah yang dilaksanakan bersamaan dimana dalam hal ini waktu dan penggunaan ruangan yang sama namun dengan mata kuliah dan dosen berbeda serta adanya jadwal tambahan misalnya dosen yang mengajar mata kuliah tersebut berhalangan hadir maka otomatis dosen akan mengadakan kulliah pengganti untuk memenuhi pertemuan sebelum ujian akhir semester [3].

Pada penelitian Dung-Ying Lin \& Hui-Yen Liu, "Combined Ship Allocation, Routing And Freight Assignment In Tramp Shipping" yang menggunakan metode algorima genetika[4]. Dimana penelitian metode algoritma genetika untuk mengalokasikan kapal tramp dengan mempertimbangkan rute dan penugasan kapal namun hal ini masih belum bisa bekerja dengan maksimal dalam menangani rute penjadwalan kapal.

Penelitian selanjutnya adalah Triwiyanto Silaban ddk dengan judul "Penjadwalan Produksi Dengan Algoritma Tabu Search"[5]. Tujuan dari penelitian adalah meminimasi makespan sehingga dapat mengurangi keterlambatan yang ada. Algoritma tabu search disertai dengan gantt chart sebagai tolak ukur penyesuaian dalam perhitungan dilakukan untuk proses penjadwalan ulang. Namun tidak ada pembanding algoritma yang digunakan sehingga belum bisa dijadikan sebagai tolak ukur yang maksimal dan penetuan jadwal pengganti.

Lian Aga Aditya dengan judul penelitian "Implementasi Algoritma Genetika Untuk Penjadwalan Mata Pelajaran Pada LMS Getsmart'[6]. Pada penelitian ini algoritma genetika untuk pada proses penjadwalan pelajaran telah menghasilkan jadwal yang cukup optimal berdasarkan perhitungan nilai fitness tertinggi pada saat proses generate tersebut dilakukan dan berdasarkan mekanisme Algoritma Genetika yang telah dibuat. Semakin banyak kelas yang terlibat dalam proses penjadwalan, maka nilai fitness yang dihasilkan akan semakin kecil, dikarenakan perhitungan pinalty untuk tabrakan jam antarkelas akan semakin besar. Pada penelitian ini hanya dalam kapasitasnya menemukan jadwal yang bentrok saja, tetapi tidak memberikan solusi waktu pengganti pada jadwal yang bentrok tersebut.

Yadav, "Study of the various selection technique in Genetic Algorithm" adalah teknik pencarian, optimisasi, dan pembelajaran mesin adaptif yang berulang yang didasarkan pada prinsip-prinsip seleksi alam, dan mampu menemukan solusi untuk masalah sulit [7]. Namun pada penelitian ini belum bisa menghasilkan jadwal yang tidak bentrok dengan jadwal lainnya. Sehingga belum dapat bekerja dengan maksimal.

Selain Algoritma Genetika juga terdapat Algoritma metaheuristic lainnya yang banyak digunakan penelitian dalam menyelesaikan optimasi penjadwalan, seperti algoritma ant colony optimization, algoritma quantum genetic, simulated annealing dan particle swarm optimization. Namun pada penelitian diatas hanya sebatas menangani masalah optimasi waktu dalam penggunaan memori.

Sehingga dengan melihat persamalahan diatas akan rumit apabila terjadi hal tersebut karena proses penyusunan jadwal yang masih tergolong manual meskipun dibuat dalam bentuk spreadsheet namun untuk melihat jadwal mata kuliah tambahan masih sulit dideteksi terkadang tidak tersorot meskipun setiap spredsheet tersebut sudah dibuat sedemikian unik namun hal tersebut tidak bisa berjalan normal untuk menentukan jadwal pengganti kuliah sehingga memerlukan waktu yang cukup lama untuk mencari data ruangan dan waktu yang kosong pada spredsheet kolom jadwal matakuliah. Sehingga penulis tertarik untuk membuat suatu sistem untuk memecahkan masalah penjadwalan dengan memanfaat metode fitness dan tabu search untuk mempermudah proses jadwal kuliah tambahan agar jadwal yang terbentuk dari awal semester dapat berjalan sesuai dengan apa yang telah ditetapkan dan tidak ada lagi jadwal tambahan pada saat memasuki minggu tenang sebelum ujian akhir semester berlangsung [8].

Melihat dari latar belakang tersebut maka pada penelitian ini akan dilakukan Perbandingan Kinerja metode Fitness of Spring dan Algoritma Tabu Search untuk mengganti jadwal perkuliahan studi kasus di Universitas Andi Djemma Palopo.

\section{Metode Penelitian}

Fitness merupakan salah satu model metode yang ada dalam Algorirtma Genetika yang digunakan untuk melakukan suatu pengoptimalan dengan yang sebelumnya melewati beberapa tahap [9]-[11]:

a. Selection, merupakan penilaian awal yang dilakukan terhadap nilai fitness untuk memperoleh kualitas nilai yang terstruktur.

b. CrossOver, merupakan proses pemilihan struktur yang akan di crossover yang telah diatur dengan meggunakan parameter Algortima Genetika pada saat melakukan persilangan 2 struktur yang berbeda untuk mendapatkan nilai fitness.

c. Mutation, merupakan proses yang dilakukan setelah proses pertukaran struktur dalam 2 kelompok yang berbeda 
Tabu Search adalah metode Heuristik berbasis lokal yang digunakan dalam proses optimasi pecarian dari solusi satu kesolusi lainnya untuk memecahkan suatu permsalahan yang kompleks dengan cara menemukan solusi yang tepat dan dalam solusi tersebut tidak terdapat pelanggaran.

\section{A. Menentukan Value of Fitness}

Untuk mengetahui nilai fitness dalam suatu struktur yang sama maka digunakan algoritma fitnes of spring. Nilai yang diperoleh nantinya akan digunakan sebagai tolak ukur seberapa banyak pelanggaran yang ada pada penggunaan jadwal yang telah disusun sejak awal semester. Baik itu pelanggaran berat maupun pelanggaran ringan. Berikut ini ketentuan batasan untuk memperoleh Value of Fitness [12]:

1) Pelanggaran Ringan

Bertepatan dengan jadwal dosen mengajar pada mata kuliah lain dengan ruangan yang sama.

2) Pelanggaran Berat

Dimana ada penggunaan ruangan yang tadinya kosong namun diisioleh dosen dari mata kuliah lain dan pada akhirnya dosen tersebut kembali tidak dapat hadir karena berhalangan atau tiba-tiba ada kegiatan, adanya jadwal dosen pada mata kuliah lain dihari yang sama, hari dan sesi yang sama adalah hal yang paling sulit karena dalam hal ini ruangan dan dosen tersedia namun ada hari dan sesi yang sama dengan jadwal mata kuliah lain dari kelas mahasiswa yang akan mengganti jadwal perkuliahan, adanya persamaan jadwal dengan mata kuliah yang akan diganti dengan mata kuliah lain dihari tersebut. Dan yang utama adalah hari Sabtu tidak boleh ada proses perkuliahan reguler baik untuk kelas normal ataupun pengganti

Dalam penelitian ini untuk mendapatkan nilai fitness jadwal pengganti perkulihan peneliti kembali menggunakan jadwal yang sudah dibuat sebelumnya. Sehingga nilai fitness yang diperoleh adalah 1 dikarenakan tidak adanya jadwal yang sama. Namun apabila dalam implemntasinya jadwal ada sebelumnya sama maka akan terlihat perubahan dalam penentuan nilai fitness yang merupakan hasil dari gabungan antara metode fitness dan Algoritma Tabu Search sehingga dalam setiap pelanggaran yang dilakukan dalam proses implementasi akan dikenakan sanksi. Berdasarkan persamaan (1) yang digunakan untuk memperoleh nilai fitness, yaitu [10]:

$$
f(x)=\left(\frac{1}{1+\left(\sum p d+\sum p r+\sum p h+\sum p s+\sum p m k\right)}\right)
$$

Keterangan:

$f(x) \quad=$ Jumlah struktur dalam satu kelompok

pd = Jadwal pengganti yang sama dengan mata kuliah lain

pr = Penggunaan ruangan yang sama

ph = Hari yang sama

ps $\quad=$ Sesi yang sama

pmk = Semua kelompok yang ada dalam satu struktur sama

Berdasarkan rumus 1 yang digunakan apabila nilai fitness yang ditemukan dalam pelanggaran jadwal yang telah ditentukan kecil, maka hasil tersebut adalah baik. Dan apabila sebaliknya nilai yang diperoleh semakin tinggi maka peluang pelanggaran yang ada pada jadwal tersebut semakin besar pula. Dan hal ini menunjukan bahwa jadwal yang telah disusun dari awal tidak maksimal.

B. Proses seleksi data

Proses seleksi dilakukan dimulai dari pengecekan data awal sampai batas jumlah data yang telah ditentukan dalam kelompok struktur

C. Persilangan

Menentukan titik objek yang ada dalam struktur tersebut untuk menghasilkan struktur baru dalam objek tersebut.

Tabel 1. Jadwal utama(X)

\begin{tabular}{ll} 
KD & HARI_1 \\
\hline KD & MATA KULIAH_1 \\
\hline KD & DOSEN_1 \\
\hline KD & KELAS_1 \\
\hline KD & RUANGAN_1
\end{tabular}

Setelah proses seleksi maka proses selanjutnya adalah proses persilangan. Metode yang digunakan salah satunya adalah one-cut point, yaitu memilih secara acak satu struktur utama berdasarkan jadwal yang telah ditentukan kemudian saling menukar struktur untuk memproleh struktur baru yang dibentuk berdsarkan hasil persilangan yang diambil menggunakan rumus objektif pada nilai fitness dengan menggunakan rumus persamaan (2) [13]:

$$
(x+2 y+3 z+4 a)-40
$$


Nilai yang terdapat pada tabel utama diatas dipilih secara acak dari hasil persilangan yang dipengaruhi oleh parameter angka yang diperoleh pada nilai fitness. Sehingga dari hasil perhitungan struktur utama dapat dilihat Tabel 1, terbentuklah tabel baru yan ditunjukkan pada Tabel 2.

Tabel 2. Jadwal utama(Y)

\begin{tabular}{ll} 
KD & HARI_2 \\
\hline KD & MATA KULIAH_2 \\
\hline KD & DOSEN_2 \\
\hline KD & KELAS_2 \\
\hline KD & RUANGAN_2
\end{tabular}

Sehingga dari penggabungan Tabel 1 dan Tabel 2, terbentuklah struktur baru yang akan digunakan pada tabel (x, y dan z).

Tabel 3. Penggabungan Jadwal (X, Y, Z)

\begin{tabular}{ccc}
$\mathbf{0}$ & $\mathbf{1}$ & $\mathbf{2}$ \\
\hline KD & HARI_1 & HARI_2 \\
\hline KD & MATA KULIAH_1 & MATA KULIAH_2 \\
\hline KD & DOSEN_1 & DOSEN_2 \\
\hline KD & KELAS_1 & KELAS_2 \\
\hline KD & RUANGAN_1 & RUANGAN_2 \\
\hline
\end{tabular}

Tabel 3 menunjukan bahwa hari,mata kuliah, dosen kelas dan ruangan tersebut dapat digunakan untuk mengganti jadwal mata kuliah dengan tidak menganggu jadwal yang telah ada.

\section{Mutation}

Mutasi merupakan proses penukaran data yang dilakukan secara random dengan mengubah kelompok salah satu struktur dari hasil persilangan data yang terdapat pada jadwal X, Y, Z pada Tabel 3. Dengan tujuan untuk tetap mempertahankan data sama yang dalam strktur tersebut.

Tabel 4. Jadwal Utama (X) Setelah mutasi

\begin{tabular}{lc} 
KD & HARI_1 \\
KD & MATA KULIAH_2 \\
\hline KD & DOSEN_1 \\
\hline KD & KELAS_1 \\
\hline KD & RUANGAN_1
\end{tabular}

Hasil dari perhitungan nilai fitness yang diperoleh menunjukan angka terbaik adalah 1. Setelah melewati proses mutasi lihat Tabel 4, yang diambil dari 8 struktur persilangan menggunakan persamaan (3).

$$
\text { Rumus untuk mencari probabilitas: P[i] = fitness[i] / total_fitness }
$$

Selanjutnya data yang yang diambil dari struktur terbaik ini akan diproses menggunakan Algoritma Tabu Search.

\section{E. Tabu Search}

Proses neighbor pada Tabu Search merupakan proses persilangan kelompok dari beberapa struktur seperti halnya pada proses penentuan nilai fitness[14], [15]. Namun pada Tabu Search ini digunakan untuk meningkatkan individu terbaik yang nantinya akan ditemukan dalam proses perhitungan dan akan disimpan kedalam Tabu List[16]. Tabel 5 merupakan proses pengambilan nilai menggunakan Algortima Tabu Search sebelum menetukan hasil dari struktur tabel x,y,z. Tabel 5 merupakan hasil dari Algoritma Tabu Search yang telah disimpan kedalam Tabu List.

\begin{tabular}{|c|c|c|}
\hline KD & HARI_1 & KD \\
\hline KD & MATA KULIAH_1 & KD \\
\hline KD & DOSEN_1 & $\mathrm{KD}$ \\
\hline KD & KELAS_1 & KD \\
\hline KD & RUANGAN_2 & $\mathrm{KD}$ \\
\hline KD & HARI_2 & KD \\
\hline KD & MATA KULIAH_2 & KD \\
\hline KD & DOSEN_2 & KD \\
\hline KD & KELAS_2 & KD \\
\hline KD & RUANGĀN 1 & $\mathrm{KD}$ \\
\hline
\end{tabular}




\section{F. Data penelitian}

Data-data yang digunakan pada penelitian ini merupakan jdwal perkuliahan semester genap tahun ajaran 2019/2020 pada Fakultas Teknik Program Studi Teknik Informatika Universitas Andi Djemma Palopo. Berikut ini pada Tabel 6, Tabel 7 dan Tabel 8, merupakan beberapa data yang digunakan dalam penelitian:

Tabel 6. Jadwal Sesmester Gasal T.A. 2019/2020

\begin{tabular}{|c|c|c|c|c|c|c|}
\hline Hari & Waktu & Mata Kuliah & Dosen & Kelas & Semester & Ruangan \\
\hline \multirow{12}{*}{$\begin{array}{l}\text { 䍐 } \\
\text { Z }\end{array}$} & $08.00-$ & Elektronika Digital & Rinto Suppa, S.Si., M.Pd. & TI1 & III & $\mathrm{C} 2$ \\
\hline & 09.40 & Pemrograman Visual & Aishiyah Saputri Laswi, S.Kom., M.Kom. & TI2 & III & $\mathrm{C} 4$ \\
\hline & & Pendidikan Agama Islam & Hasnahwati, S.Pd.I., M.Pd.I. & TI1 & I & $\mathrm{C} 11$ \\
\hline & & Pendidikan Pancasila & $\begin{array}{l}\text { Dr. H. Ishak Runi, MM., M.Si. } \\
\text { Risman Setiawan, SH., MH. }\end{array}$ & TI3 & I & $\mathrm{C} 12$ \\
\hline & & WSBD dan Keluwuan & $\begin{array}{l}\text { Ir. Andi Idrus, M.Si. } \\
\text { Hamka, S.Psi., MM. }\end{array}$ & TI2 & I & $\mathrm{C} 13$ \\
\hline & & & & & & $\mathrm{C} 14$ \\
\hline & $09.50-$ & Elektronika Digital & Rinto Suppa, S.Si., M.Pd. & TI2 & III & $\mathrm{C} 2$ \\
\hline & 11.30 & Pemrograman Visual & Aishiyah Saputri Laswi, S.Kom., M.Kom. & TI1 & III & $\mathrm{C} 4$ \\
\hline & & Pendidikan Agama Islam & Hasnahwati, S.Pd.I., M.Pd.I. & TI2 & I & $\mathrm{C} 11$ \\
\hline & & Pendidikan Pancasila & $\begin{array}{l}\text { Dr. H. Ishak Runi, MM., M.Si. } \\
\text { Risman Setiawan, SH., MH. }\end{array}$ & TI1 & I & $\mathrm{C} 12$ \\
\hline & & WSBD dan Keluwuan & $\begin{array}{l}\text { Ir. Andi Idrus, M.Si. } \\
\text { Hamka, S.Psi., MM. }\end{array}$ & TI3 & I & $\mathrm{C} 13$ \\
\hline & & Pengenalan Pola & Hisma Abduh, S.Kom., M.Cs. & TI3-Gab & Gab & $\mathrm{C} 14$ \\
\hline \multirow{9}{*}{$\begin{array}{l}\text { 胃 } \\
\text { Z }\end{array}$} & $13.00-$ & Pengenalan Pola & Hisma Abduh, S.Kom., M.Cs. & TI1 & III & $\mathrm{C} 2$ \\
\hline & 14.40 & Sistem Operasi & Muhlis Muhallim, S.Kom., M.Cs. & TI2 & III & $\mathrm{C} 4$ \\
\hline & & Pendidikan Agama Islam & Hasnahwati, S.Pd.I., M.Pd.I. & TI3 & I & $\mathrm{C} 11$ \\
\hline & & Pendidikan Pancasila & $\begin{array}{l}\text { Dr. H. Ishak Runi, MM., M.Si. } \\
\text { Risman Setiawan, SH., MH. }\end{array}$ & TI2 & I & $\mathrm{C} 12$ \\
\hline & & WSBD dan Keluwuan & $\begin{array}{l}\text { Ir. Andi Idrus, M.Si. } \\
\text { Hamka, S.Psi., MM. }\end{array}$ & TI1 & I & $\mathrm{C} 13$ \\
\hline & & Pengolahan Citra Digital & Rinto Suppa, S.Si., M.Pd. & TI-Gab & Pil-VII & $\mathrm{C} 14$ \\
\hline & $14.50-$ & Pengenalan Pola & Hisma Abduh, S.Kom., M.Cs. & TI2 & III & $\mathrm{C} 2$ \\
\hline & 16.30 & Sistem Operasi & Muhlis Muhallim, S.Kom., M.Cs. & TI1 & III & $\mathrm{C} 4$ \\
\hline & & Listrik dan Magnet & Rinto Suppa, S.Si., M.Pd. & TI-Gab & Pil-V & C14 \\
\hline \multirow{7}{*}{ 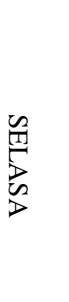 } & $08.00-$ & Kalkulus & Apriyanto, S.Pd., M.Sc. & TI3 & I & $\mathrm{C} 2$ \\
\hline & 09.40 & Interaksi Manusia dan Komputer & Ahmad Ali Hakam Dani, S.Si., M.T.I. & TI1 & III & $\begin{array}{c}\mathrm{C} 4 \\
\mathrm{C} 11\end{array}$ \\
\hline & & Perangkat Lunak Aplikasi & Solmin Paembonan, S.Kom., M.Cs. & TI1 & I & $\mathrm{C} 12$ \\
\hline & & Multimedia & Aishiyah Saputri Laswi, S.Kom., M.Kom. & TI1 & Pil-VII & $\mathrm{C} 13$ \\
\hline & & Interaksi Manusia dan Komputer & Ahmad Ali Hakam Dani, S.Si., M.T.I. & TI2 & III & $\mathrm{C} 4$ \\
\hline & & Perangkat Lunak Aplikasi & Solmin Paembonan, S.Kom., M.Cs. & TI2 & I & $\mathrm{C} 12$ \\
\hline & & Multimedia & Aishiyah Saputri Laswi, S.Kom., M.Kom. & TI2 & Pil-VII & C13 \\
\hline \multirow{7}{*}{ 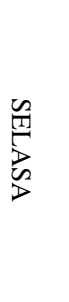 } & $13.00-$ & Interaksi Manusia dan Komputer & Ahmad Ali Hakam Dani, S.Si., M.T.I. & TI3-Gab & Gab & $\mathrm{C} 2$ \\
\hline & 14.40 & Administrasi Server & Muhlis Muhallim, S.Kom., M.Cs. & TI2 & $\mathrm{V}$ & $\begin{array}{c}\mathrm{C} 4 \\
\mathrm{C} 11\end{array}$ \\
\hline & & Perangkat Lunak Aplikasi & Solmin Paembonan, S.Kom., M.Cs. & TI3 & I & $\mathrm{C} 12$ \\
\hline & & Kecerdasan Buatan & Aishiyah Saputri Laswi, S.Kom., M.Kom. & TI1 & $\mathrm{V}$ & $\mathrm{C} 13$ \\
\hline & $14.50-$ & Sistem Testing dan Implementasi & Solmin Paembonan, S.Kom., M.Cs. & TI-Gab & Pil-V & $\mathrm{C} 2$ \\
\hline & 16.30 & Administrasi Server & Muhlis Muhallim, S.Kom., M.Cs. & TI1 & $\mathrm{V}$ & $\mathrm{C} 4$ \\
\hline & & Kecerdasan Buatan & Aishiyah Saputri Laswi, S.Kom., M.Kom. & TI2 & V & $\mathrm{C} 13$ \\
\hline \multirow{10}{*}{$\underset{C}{\mathbb{C}}$} & $08.00-$ & Pengantar Teknologi Informasi & Ahmad Ali Hakam Dani, S.Si., M.T.I. & TI1 & I & $\mathrm{C} 2$ \\
\hline & 09.40 & Teori Bahasa dan Automata & Solmin Paembonan, S.Kom., M.Cs. & TI1 & $\mathrm{V}$ & $\mathrm{C} 4$ \\
\hline & & $\begin{array}{l}\text { Algoritma Pemrograman \& } \\
\text { Struktur Data }\end{array}$ & Hisma Abduh, S.Kom., M.Cs. & TI3 & I & C11 \\
\hline & & Bahasa Indonesia & $\begin{array}{l}\text { Chece Djafar, S.Pd., M.Pd. } \\
\text { Harmita Sari, S.Pd., M.Pd. }\end{array}$ & TI2 & I & $\mathrm{C} 13$ \\
\hline & $09.50-$ & Pengantar Teknologi Informasi & Ahmad Ali Hakam Dani, S.Si., M.T.I. & TI2 & I & $\mathrm{C} 2$ \\
\hline & 11.30 & Teori Bahasa dan Automata & Solmin Paembonan, S.Kom., M.Cs. & TI2 & $\mathrm{V}$ & $\mathrm{C} 4$ \\
\hline & & $\begin{array}{l}\text { Algoritma Pemrograman \& } \\
\text { Struktur Data }\end{array}$ & Hisma Abduh, S.Kom., M.Cs. & TI1 & I & $\mathrm{C} 11$ \\
\hline & & & & & & $\mathrm{C} 12$ \\
\hline & & Bahasa Indonesia & $\begin{array}{l}\text { Chece Djafar, S.Pd., M.Pd. } \\
\text { Harmita Sari, S.Pd., M.Pd. }\end{array}$ & TI3 & I & $\mathrm{C} 13$ \\
\hline & & Sistem Basis Data & Rosdiana, ST., M.Kom. & TI3-Gab & Gab & C14 \\
\hline
\end{tabular}




\begin{tabular}{|c|c|c|c|c|c|c|}
\hline Hari & Waktu & Mata Kuliah & Dosen & Kelas & Semester & Ruangan \\
\hline \multirow{10}{*}{ 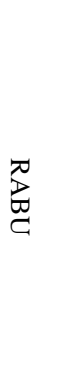 } & $13.00-$ & Pengantar Teknologi Informasi & Ahmad Ali Hakam Dani, S.Si., M.T.I. & TI3 & I & $\mathrm{C} 2$ \\
\hline & 14.40 & Statistika dan Probabilitas & Apriyanto, S.Pd., M.Sc. & TI1 & V & $\mathrm{C} 4$ \\
\hline & & $\begin{array}{c}\text { Algoritma Pemrograman \& } \\
\text { Struktur Data }\end{array}$ & Hisma Abduh, S.Kom., M.Cs. & TI2 & I & $\mathrm{C} 11$ \\
\hline & & Jaringan Nirkabel & Muhlis Muhallim, S.Kom., M.Cs. & TI1 & Pil-V & $\mathrm{C} 12$ \\
\hline & & Sistem Basis Data & Rosdiana, ST., M.Kom. & TI2 & III & $\mathrm{C} 13$ \\
\hline & & & & & & $\mathrm{C} 14$ \\
\hline & $14.50-$ & Logika Fuzzy & Ahmad Ali Hakam Dani, S.Si., M.T.I. & TI-Gab & Pil-VII & $\mathrm{C} 2$ \\
\hline & 16.30 & Statistika dan Probabilitas & Apriyanto, S.Pd., M.Sc. & $\mathrm{TI} 2$ & V & $\mathrm{C} 4$ \\
\hline & & Jaringan Nirkabel & Muhlis Muhallim, S.Kom., M.Cs. & TI2 & Pil-V & $\mathrm{C} 12$ \\
\hline & & Sistem Basis Data & Rosdiana, ST., M.Kom. & TI1 & III & $\mathrm{C} 13$ \\
\hline \multirow{7}{*}{ 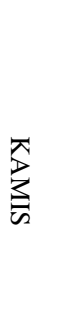 } & $08.00-$ & Mikrokontroler & Rinto Suppa, S.Si., M.Pd. & TI1 & V & $\mathrm{C} 2$ \\
\hline & 09.40 & Kalkulus & Apriyanto, S.Pd., M.Sc. & TI1 & I & $\mathrm{C} 4$ \\
\hline & & Rekayasa Perangkat Lunak & Muh. Nashir Takbir, S.Kom., M.Pd. & TI2 & $\mathrm{V}$ & $\begin{array}{l}\mathrm{C} 11 \\
\mathrm{C} 12\end{array}$ \\
\hline & $09.50-$ & Mikrokontroler & Rinto Suppa, S.Si., M.Pd. & $\mathrm{TI} 2$ & V & $\mathrm{C} 2$ \\
\hline & 11.30 & Kalkulus & Apriyanto, S.Pd., M.Sc. & TI2 & I & $\mathrm{C} 4$ \\
\hline & & Bahasa Indonesia & $\begin{array}{l}\text { Chece Djafar, S.Pd., M.Pd. } \\
\text { Harmita Sari, S.Pd., M.Pd. }\end{array}$ & TI1 & I & $\mathrm{C} 11$ \\
\hline & & Rekayasa Perangkat Lunak & Muh. Nashir Takbir, S.Kom., M.Pd. & TI1 & V & $\mathrm{C} 12$ \\
\hline \multirow{2}{*}{ 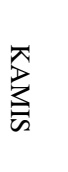 } & $13.00-$ & Riset Operasi & Apriyanto, S.Pd., M.Sc. & TI1 & Pil-V & $\mathrm{C} 2$ \\
\hline & $\begin{array}{c}14.50- \\
16.30\end{array}$ & Riset Operasi & Apriyanto, S.Pd., M.Sc. & TI2 & Pil-V & $\mathrm{C} 2$ \\
\hline \multirow{2}{*}{$\frac{3}{3}$} & $\begin{array}{c}08.00- \\
09.40\end{array}$ & Kewirausahaan & Budiawan Sulaeman, ST., MT. & TI1 & $\mathrm{V}$ & $\mathrm{C} 2$ \\
\hline & $\begin{array}{c}09.50- \\
11.30\end{array}$ & Kewirausahaan & Budiawan Sulaeman, ST., MT. & TI2 & V & $\mathrm{C} 2$ \\
\hline \multirow{6}{*}{$\frac{3}{3}$} & $\begin{array}{c}13.30- \\
15.10\end{array}$ & $\begin{array}{c}\text { Manajeman Proyek Perangkat } \\
\text { Lunak }\end{array}$ & Budiawan Sulaeman, ST., MT. & TI1 & Pil-VII & $\mathrm{C} 2$ \\
\hline & $\begin{array}{c}15.20- \\
17.00\end{array}$ & $\begin{array}{c}\text { Manajeman Proyek Perangkat } \\
\text { Lunak }\end{array}$ & Budiawan Sulaeman, ST., MT. & TI2 & Pil-VII & $\mathrm{C} 2$ \\
\hline & $\begin{array}{c}08.00- \\
10.00\end{array}$ & $\begin{array}{c}\text { Pendidikan Agama Kristen } \\
\text { Protestan }\end{array}$ & Yehezkiel Ruben Pasangkin, S.Pd.K & A & I & D203 \\
\hline & & $\begin{array}{c}\text { Pendidikan Agama Kristen } \\
\text { Katolik }\end{array}$ & Selvianus Silas, S.Pd., M.Pd. & Gab & I & D204 \\
\hline & $\begin{array}{c}10.00- \\
12.00\end{array}$ & $\begin{array}{c}\text { Pendidikan Agama Kristen } \\
\text { Protestan }\end{array}$ & Yehezkiel Ruben Pasangkin, S.Pd.K & B & I & D203 \\
\hline & & Pendidikan Agama Hindu & Darmadi Putra, S.Sos. & $\mathrm{Gab}$ & I & D204 \\
\hline
\end{tabular}

Tabel 7. Data Penelitian

\begin{tabular}{lc} 
Jumlah dosen sesmster genap & $\mathbf{1 9}$ \\
\hline Jumlah mata kuliah sesmester genap & 28 \\
\hline Jumlah hari dalam penjadwalan & 6 \\
\hline Jumlah penjadwalan di awal & 72
\end{tabular}

Tabel 8. Data Ruangan Yang Terpakai

\begin{tabular}{ccccccc}
\hline Ruangan & Senin & Selasa & Rabu & Kamis & Jum'at & Sabtu \\
\hline Ruangan Terpakai & 6 & 5 & 5 & 3 & 1 & 2 \\
Ruangan Kosong & 2 & 3 & 3 & 5 & 7 & 6 \\
\hline
\end{tabular}

\section{Hasil dan Pembahasan}

Untuk menemukan nilai sebagai ukuran terbaik pada Algoritma Genetika dengan menggunakan rumus (1) bahwa setiap kombinasi pada proses inisialisasi pembentukan struktur antara nilai probabilitas dan hasil persilangan yang telah diseleksi secara acak sebanyak 8 kali menghasilkan nilai uji dengan rata-rata 
nilai fitness sebesar 1.8978 berdasarkan $0.414+0.2+0.25+0.5+1+0.6666+0.5+0.2 / 1$. Dimana nilai diatas diperoleh dari hasil inisialiasi awal pembentukan struktur untuk menentukan nilai terbaik. K (Kuliah ke-), R (Ruangan yang akan digunakan), W (Waktu Kuliah) dan H (Hari Kuliah) data pada Tabel 9 dibentuk dari hasil rujukan jadwal semester gasal pada Tabel 6.

Tabel 9. Prosen Inisialisasi

\begin{tabular}{ccccc}
\hline NO & K & R & W & H \\
\hline $\mathbf{1}$ & 2 & C14 & 4 & 1 \\
$\mathbf{2}$ & 4 & C11 & 5 & 1 \\
$\mathbf{3}$ & 3 & C13 & 4 & 2 \\
$\mathbf{4}$ & 3 & C12 & 3 & 3 \\
$\mathbf{5}$ & 4 & C2 & 4 & 3 \\
$\mathbf{6}$ & 5 & C11 & 5 & 3 \\
$\mathbf{7}$ & 1 & C 4 & 2 & 5 \\
$\mathbf{8}$ & 2 & C11 & 2 & 5 \\
$\mathbf{9}$ & 2 & C14 & 4 & 1 \\
\hline
\end{tabular}

Pengujian kedua membandingkan nilai fitness pada tiap struktur yang telah diketahui nilainya. berdasarkan hasil pengujian banyak nilai fitness yang tidak konsisten. Sedangkan pada Algoritma Tabu Search nilai yang diperoleh tetap pada nilai awal tidak berulang-ulang hasil penjadwalan dapat berjalan secara optimal dengan menggunakan 2 tolak ukur nilai terbaik 0.5269 dan 0.2634 . berdasarkan $\mathrm{f}=1 / 1.8978$ dan $\mathrm{f}=0.5 / 1.897$ dan batasan nilai maksimum diperoleh dari nilai akhir Algoritma Tabu Search adalah 15 berdasarkan rujukan yang terdapat pada Tabel 7. Kemudian dimplementasikan pada Gambar 1.

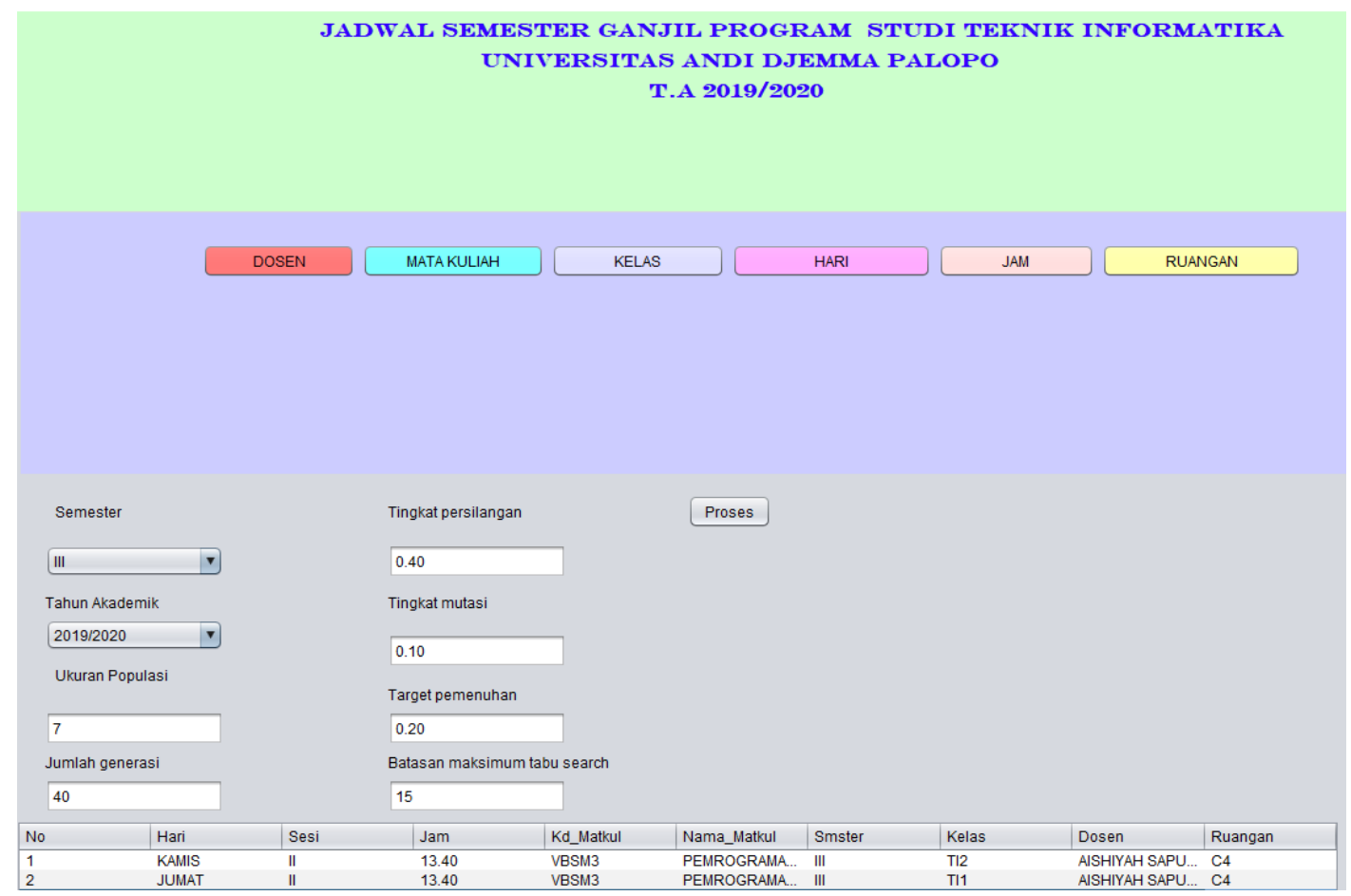

Gambar 1. Hasil implementasi perbandingan alorifitness dan tabu search

Berdasarkan hasil implementasi pada aplikasi penjadwalan diatas maka masing-masing kelas dan mata kuliah yang yang akan melakukan kuliah pengganti terlebih dahulu akan diproses melalui ukuran populasi, jumlah generasi, tingkat persilangan, tingkat mutase dan target pemenuhan sehingga menghasilkan Batasan nilai maksimum yaitu 15 dimana nilai yang diperoleh rendah namun bisa digunakan secara maksimal untuk menentukan jadwal pengganti perkuliahan. Tabu search menampilkan data dari hasil optimasi pencarian beberapa komponen yang melakukan beberapa literasi sebelumnya.

\section{Kesimpulan dan saran}

Nilai yang diperoleh dari hasil implementasi kedua algoritma di atas, dengan menggunakan algoritma fitness adalah 40 sedangkan untuk tabu search batasan nilai maksimum yang diperoleh dinilai akhir adalah 15 berdasarkan urutan dari jadwal mata kuliah sebelumnya dan mata kuliah yang akan diganti kehadirannya. Dengan demikian nilai yang diperoleh dengan menggunakan algoritma tabu search adalah dalam kategori 
normal dibanding dengan algoritma fitness yang berubah-ubah. Dengan demikian peneliti dapat menyimpulkan bahwa nilai yang diperoleh tabu search lebih kecil sehingga baik digunakan untuk menentukan penjadwalan. Adapun saran dari peneliti, bahwa jadwal yang digunakan tidak berubah-ubah. Dan peningkatan kecepatan dalam proses running program yang akan memberikan solusi dalam pemecahan masalah penentuan kuliah jadwal pengganti agar tidak terjadi kesalahan dalam penentuan kelas pengganti.

\section{Daftar Pustaka}

[1] R. Hartadi and A. Hidayat, "Perancangan Aplikasi Penjadwalan Mata Kuliah (Studi Kasus : STMIK Provisi Semarang)," J. Bianglala Inform., vol. 4, no. 1, pp. 31-40, 2016.

[2] A. Laksono, M. Utami, and Y. Sugiarti, "Sistem Penjadwalan Kuliah Menggunakan Metode Algoritma Genetika (Studi Kasus: Fakultas Kedokteran Dan Kesehatan Universitas Muhammadiyah Jakarta)," Stud. Inform. J. Sist. Inf., vol. 9, no. 2, pp. 177-188, 2018, doi: 10.15408/sijsi.v9i2.7647.

[3] J. M. Simbolon and Suyanto, "Algoritma genetika dengan pengkodean langsung dan mutasi terarah untuk penjadwalan kuliah," 2012.

[4] D. Y. Lin and H. Y. Liu, "Combined ship allocation, routing and freight assignment in tramp shipping," Transp. Res. Part E Logist. Transp. Rev., vol. 47, no. 4, pp. 414-431, 2011, doi: 10.1016/j.tre.2010.12.003.

[5] T. Silaban et al., "Penjadwalan produksi dengan algoritma tabu search," Ind. Eng. Conf. Yogyakarta, pp. 1-9, 2014.

[6] L. A. Aditya, "Implementasi Algoritma Genetika untuk Penjadwalan Mata Pelajaran pada LMS GetSmart," J. Mantik Penusa, vol. 21, no. 1, pp. 65-70, 2017.

[7] S. L. Yadav and A. Sohal, "Study of the various selection," no. May, 2018.

[8] D. Zai, H. Budiati, S. S. Berutu, T. Informatika, F. Sains, and U. K. Immanuel, "Lokasi Pariwisata Di Nias Dengan Metode Breadth First Search dan Tabu Search,” InFact, vol. 1, no. 2, pp. 30-41, 2016.

[9] R. M. Puspita, A. Arini, and S. U. Masrurah, "Pengembangan Aplikasi Penjadwalan Kegiatan Pelatihan Teknologi Informasi Dan Komunikasi Dengan Algoritma Genetika (Studi Kasus: Bprtik)," J. Online Inform., vol. 1, no. 2, pp. 76-81, 2016, doi: 10.15575/join.v1i2.43.

[10] D. Kristiadi and R. Hartanto, "Genetic Algorithm for lecturing schedule optimization," IJCCS (Indonesian J. Comput. Cybern. Syst., vol. 13, no. 1, p. 83, 2019, doi: 10.22146/ijccs.43038.

[11] S. Ginoria, G. L. Samuel, and G. Srinivasan, "Optimisation of a machine loading problem using a genetic algorithm-based heuristic," Int. J. Product. Qual. Manag., vol. 15, no. 1, pp. 36-56, 2015, doi: 10.1504/IJPQM.2015.065984.

[12] M. Muliadi, "Pemodelan Algoritma Genetika," Pemodelan Algoritm. Genet. Pada Sist. Penjadwalan Perkuliahan Prodi Ilmu Komput. Univ. Lambungmangkurat, vol. 01, no. 01, pp. 67-78, 2014.

[13] D. S. Donoriyanto, A. S. Anam, and E. W. Pudji, "Application of genetic algorithm method on machine maintenance," J. Phys. Conf. Ser., vol. 953, no. 1, 2018, doi: 10.1088/17426596/953/1/012225.

[14] M. Miswanto, F. Pernando, and I. Aditya Firmansyah, "Implementasi Algoritma Tabu Search Untuk Mengoptimasi Penjadwalan Preventive Maintenancept Solusi Aplikasi Interaktif," vol. 2018, no. Sentika, pp. 23-24, 2018.

[15] S. Sulistiono and N. S. M. Mussafi, "Rancang Bangun Vehicle Routing Problem Menggunakan Algoritma Tabu Search," J. Fourier, vol. 4, no. 2, p. 113, 2015, doi: 10.14421/fourier.2015.42.113122.

[16] R. Stair and G. Reynolds, "Principles of Information Systems: a managerial Approach, 9th Edition," p. 10, 2010. 